\title{
PENGEMBANGAN METODE PENYULUHAN MENINGKATKAN PEMAKAIAN ALAT KONTRASEPSI
}

\author{
Development of Counseling Method to Increasing the Use of \\ Contraceptives
}

\author{
Makhrajani Majid \\ Program Studi Kesehatan Masyarakat FIKES UMPAR \\ (Nhiniekmajid@ymail.com)
}

\begin{abstract}
ABSTRAK
Program KB ke depan akan difokuskan, salah satunya pada peningkatan pemakaian alat kontrasepsi, pendewasaan usia pekawinan, menjarangkan kehamilan, pengaturan jumlah anak dan masih banyak lagi sasaran lain yang ingin ditingkatkan. Penelitian ini bertujuan mengetahui perubahan pengetahuan dan sikap masyarakat sebelum dan setelah dilakukan penyuluhan terhadap pengaturan jarak kehamilan, jumlah anak dan tingkat kesejahteraan keluarga selama pemakaian alat kontrasepsi. Desain penelitian yang digunakan adalah kuasi eksperimen dengan desain one group pretest-postest. Objek penelitian adalah ibu-ibu yang pernah menggunakan alat kontrasepsi di Kota Parepare. Jumlah responden sebanyak 117 orang. Teknik yang digunakan adalah accidental sampling. Teknik pengumpulan data dengan menggunakan kuesioner yang diberikan kepada responden sebelum dan sesudah penyuluhan. Analisis data dengan menggunakan uji t pada variabel independen. Hasil penelitian ini adalah ada perubahan tingkat pengetahuan dan sikap masyarakat sebelum dan sesudah dilakukan penyuluhan tentang jarak kehamilan, pengaturan jumlah anak dan tingkat kesejahteraan keluarga terhadap peningkatan pemakaian alat kontrasepsi di Kota Parepare.
\end{abstract}

Kata kunci : Pengetahuan, sikap, pemakaian alat kontrasepsi

\section{ABSTRACT}

Family planning program in the future will be focussed, one of that is to increasing the use of contraceptives, maturation on age of marriage, pregnancy spacing, arrange the number of child and many more the other targets are to be increased. This research aimed to know the change in knowledge and the attitude of society before and after the extended of counseling on arrangement of pregnancy spacing, arrangement of child number and level of family welfare during the use of contraceptives. Design of this research is quasi-experiment with design one group pretest - posttest. The object of this research is mothers that already have use contraceptives in Parepare. The number of respondent is 117 people. The technique that used is accidental sampling. The technique of accumulating data is using questionnaires that given to the respondent before and after counseling. Data analysis is using T test to independent variable. Conclusion in this research, there is the change of knowledge level and attitude of society before and after the extended of counseling on arrangement of pregnancy spacing, arrangement of child number and level of family welfare during increasing the use of contraceptives in Parepare.

Keywords : Knowledge, attitude, use of contraceptives 


\section{PENDAHULUAN}

Kontrasepsi merupakan teknik untuk menjarangkan kehamilan atau membatasi kehamilan. Keberhasilan dalam pemakaian kontrasepsi merupakan salah satu bukti keberhasilan program Keluarga Berencana (KB) Nasional. Keberhasilan tersebut telah diakui secara global dan bahkan menjadi model program KB di negara-negara berkembang dan itu mengantar Indonesia sebagai pusat dibidang kependudukan $\mathrm{KB}$ dan kesehatan reproduksi. ${ }^{1}$

Pelaksanaan Gerakan KB nasional selama pelita VI yang berakhir, menghadapi berbagai tantangan dan gejolak sebagai akibat terjadinya krisis ekonomi dan moneter akhir-akhir ini. ${ }^{2}$ Lebih lanjut gejolak ini dapat berdampak terhadap kesertaan ber-KB, karena ketersediaan alat dan obat kontrasepsi dari pemerintah semakin terbatas, sedangkan harga semakin melambung tinggi. ${ }^{3}$

Program KB memiliki peranan dalam menurunkan risiko kematian ibu melalui pencegahan kehamilan, penundaan usia kehamilan serta menjarangkan kehamilan dengan sasaran adalah Pasangan Usia subur (PUS). ${ }^{4}$ Salah satu strategi dari pelaksanaan program KB sendiri seperti tercantum dalam Rencana Pembangunan Jangka Menengah (RPJM) Tahun 2010-2014 adalah penggunaan Metode Kontrasepsi Jangka Panjang (MKJP) seperti IUD (Intra Uterine Devices), tubektomi/ MOW, vasektomi/MOP, dan implan. ${ }^{5}$

Jumlah Pasangan Usia Subur (PUS) di Provinsi Sulawesi Selatan yang berhasil di data pada pendataan keluarga tahun 2010 sejumlah 1.316.741 dari jumlah tersebut 50.431 PUS $(3,83 \%)$ berusia di bawah 20 tahun, 432.363 PUS (32,84\%) berusia 20-29 tahun dan 833.947 PUS lainnya $(63,33 \%)$ berusia 30 tahun keatas. Di tingkat kabupaten/kota angka persentase PUS berusia di bawah 20 tahun terendah berkisar $1,76 \%$ di Kabupaten Sinjai dan yang tertinggi $6,61 \%$ berada di Kabupaten Maros. ${ }^{6}$

Data profil BKKBN Kota Parepare Tahun 2012 jumlah peserta KB aktif yang memakai Metode Kontrasepsi Jangka Panjang (MKJP) yaitu IUD (Intra Uterine Devices ) 652 akseptor $(4,79 \%)$ dari peserta KB aktif, MOP (Medis Operasi Wanita) 986 akseptor (7,25\%) dari peserta KB aktif. Sedangkan untuk metode kontrasepsi non jangka pangjang (non-MKJP) urutan teratas ditempati oleh suntik sebanyak 5.103 akseptor dari peserta KB aktif dan kondom 1.399 akseptor $(10,28 \%)$ dari peserta KB aktif. ${ }^{7}$ Ada hubungan antara pendidikan dengan metode kontrasepsi dan ada hubungan antara pendapatan dengan metode penggunaan MKJP sebagai salah satu metode kontrasepsi jangka panjang di Indonesia yang masih rendah. Hal ini dipengaruhi oleh faktor pengetahuan, pendidikan, pendapatan, pekerjaan, takut efek samping serta ditinggal suami bekerja di luar negeri. ${ }^{8}$ Tujuan penelitian ini mengetahui perubahan tingkat pengetahuan dan sikap masyarakat sebelum dan sesudah dilakukan penyuluhan tentang pengaturan jarak kehamilan, pengaturan jumlah anak, dan tingkat kesejahteraan keluarga selama penggunaan alat kontrasespsi.

\section{BAHAN DAN METODE}

Penelitian ini dilaksanakan pada tahun 2015. Penelitian ini merupakan penelitian eksperimen dengan desain one group pretest-postest untuk mengetahui pengembangan metode penyuluhan terhadap peningkatan pemakaian alat kontrasepsi di Kota Parepare. ${ }^{9}$ Pada rancangan ini tidak ada kelompok pembanding (control), tetapi dilakukan observasi pertama (pre-test) yang memungkinkan peneliti dapat menguji perubahan yang terjadi setelah adanya perlakuan, baik perubahan pengetahuan maupun perubahan sikap. ${ }^{10}$ Sampel dalam penelitian ini adalah warga masyarakat yang berada di sekitar lokasi penelitian dan pemberian penyuluhan tentang pemakaian alat kontrasepsi di Kota Parepare sebanyak 117 masyarakat. Data primer yang diperlukan dalam penelitian ini meliputi: jarak kehamilan, jumlah anak dan tingkat kesejahteraan keluarga pada masyarakat yang diperoleh melalui wawancara langsung dengan responden kemudian penelitian ini menggunakan kuesioner yang diberikan kepada responden sebelum dan sesudah penyuluhan.

Pengisian kuesioner dilakukan sebanyak tiga kalo, yaitu pre-test 1 kali, post-test 2 kali dilaksanakan yaitu post-test 1 pada saat setelah penyuluhan dan 2 minggu kemudian diberikan lagi post-test 2 tentang jarak kehamilan, jumlah anak, tingkat kesejahteraan keluarga pada responden terhadap peningkatan pemakaian alat kontrasepsi di Kota Parepare. Hasil penelitian dianalisis dengan menggunakan distribusi frekuensi dan uji-t 
untuk melihat perbedaan sebelum dan sesudah perlakuan. Analisis ini dilakukan dengan menggunakan program SPSS 17. Keputusan uji statistik menggunakan taraf signifikan $\mathrm{p}<0,05$.

\section{HASIL}

Distribusi responden berdasarkan kelompok umur masyarakat yang tertinggi adalah 31-35 tahun mencapai 33 orang $(28,20 \%)$ dan kelompok umur yang terendah adalah 15-20 tahun hanya mencapai 10 orang $(8,54 \%)$. Tingkat pendidikan tertinggi responden mayoritas SLTA mencapai 45 orang $(38,46 \%)$, dan pendidikan terendah tamat SD hanya mencapai 15 orang (12,82\%). Untuk pekerjaan responden rata-rata hanya sebagai ibu rumah tangga, yang mencapai 43 orang $(36,76 \%)$ dan ada 8 orang $(6,83 \%)$ yang bekerja sebagai asisten rumah tangga (Tabel 1).

Tabel 1. Karakteristik Responden

\begin{tabular}{lcc}
\hline \multicolumn{1}{c}{ Karakteristik } & n (117) & \% \\
\hline $\begin{array}{l}\text { Kelompok Umur (Tahun) } \\
\text { 15-20 }\end{array}$ & 10 & 8,54 \\
$21-25$ & 21 & 17,95 \\
$26-30$ & 30 & 25,65 \\
$31-35$ & 33 & 28,20 \\
$>36$ & 23 & 19,66 \\
Pendidikan & & \\
SD & 15 & 12,82 \\
SLTP & 27 & 23,07 \\
SLTA & 45 & 38,46 \\
PT & 30 & 25,65 \\
Pekerjaan & & \\
IRT & 43 & 36,76 \\
Asisten rumah tangga & 8 & 6,83 \\
Honorer & 17 & 14,53 \\
Pegawai Negeri Sipil & 22 & 18,81 \\
Wiraswasta & 27 & 23,07 \\
& & \\
\hline
\end{tabular}

Sumber: Data Primer 2015

Berdasarkan uji statistik bahwa sebelum dilakukan penyuluhan pengetahuan masyarakat mengenai jarak kehamilan, pengaturan jumlah anak, peningkatan keluarga sejahtera pada pemakaian alat kontrasepsi untuk kriteria baik mencapai 17 orang $(14,53 \%)$, kriteria cukup 35 orang $(29,91 \%)$ dan kriteria kurang mencapai 65 orang $(55,56 \%)$. Setelah dilakukan post 1 terjadi perubahan pengetahuan kepada masyarakat hal ini ditan- dai dengan hasil sebagai berikut untuk kriteria baik meningkat mencapai 37 orang $(31,62 \%)$, kriteria cukup 54 orang $(46,15 \%)$ dan untuk kriteria kurang 26 orang $(22,23 \%)$. Kembali mengalami pe- ningkatan pengetahuan setelah dilakukan post 2 , kriteria baik 71 orang $(60,68 \%)$, cukup 33 orang $(28,20 \%)$ dan kriteria kurang 13 orang $(11,12 \%)$ (Tabel 2).

Berdasarkan uji statistik bahwa sebelum dilakukan penyuluhan sikap responden mengenai jarak kehamilan, pengaturan jumlah anak, peningkatan keluarga sejahtera terhadap peningkatan alat kontrasepsi nilai pre-test untuk kriteria baik mencapai 14 orang $(11,96 \%)$, cukup 46 orang $(39,32 \%)$ dan kurang 57 orang $(48,72 \%)$, setelah dilakukan post 1 maka hasil untuk kriteria baik mencapai 36 orang $(30,77 \%)$, kriteria cukup 50 orang $(42,74 \%)$ dan kriteria kurang 31 orang $(26,49 \%)$. Setelah dilakukan post 2 kembali mengalami peningkatan untuk kriteria baik hingga mencapai 55 orang $(47,00 \%)$, untuk kriteria cukup 42 orang $(35,90 \%)$ dan untuk kriteria kurang 20 orang $(17,10 \%)$ (Tabel 3).

Berdasarkan uji statistik untuk mengukur perubahan skor hasilnya menunjukkan bahwa terjadi peningkatan rata-rata skor pengetahuan responden mengenai peningkatan pemakaian alat kontrasepsi setelah diberikan edukasi (post-test 1) dari 3,25 poin menjadi 8,07 poin. Juga terjadi peningkatan rata-rata skor sikap yaitu dari 5,01 poin menjadi 8,28 poin. Sedangkan pada posttest 2 juga terjadi peningkatan rata-rata skor pengetahuan responden mengenai pemakaian alat kontrasepsi setelah diberikan edukasi dari 8,07 poin menjadi 8,53 poin. Juga terjadi peningkatan rata-rata skor sikap yaitu dari 8,28 point menjadi 8,68 poin (Tabel 3).

\section{PEMBAHASAN}

Pengetahuan merupakan hasil dari tahu yang terjadi setelah orang melakukan penginderaan terhadap suatu objek tertentu. Penginderaan terjadi melalui panca indra manusia yaitu penglihatan, penciuman, rasa, dan raba. Sebagian besar pengetahuan manusia diperoleh melalui mata dan telinga. Pengetahuan merupakan suatu domain yang sangat penting untuk terbentuknya suatu tindakan seseorang. Suatu penelitian mengatakan bahwa perilaku yang didasari oleh pengetahuan 
Tabel 2. Distribusi Responden Berdasarkan Kriteria Skor Pengetahua dan Sikap tentang Jarak Kehamilan, Pengaturan Jumlah Anak, Peningkatan Keluarga Sejahtera pada Pemakaian Alat Kontrasepsi

\begin{tabular}{lcccccc}
\hline \multirow{2}{*}{ Variabel } & \multicolumn{2}{c}{ Pre } & \multicolumn{2}{c}{ Post I } & \multicolumn{2}{c}{ Post II } \\
\cline { 2 - 7 } & $\mathbf{n}$ & $\mathbf{\%}$ & n & \% & n & \% \\
\hline Pengetahuan & & & & & & \\
$\quad$ Baik & 17 & 14,53 & 37 & 31,62 & 71 & 60,68 \\
$\quad$ Cukup & 35 & 29,91 & 54 & 46,15 & 33 & 28,20 \\
$\quad$ Kurang & 65 & 55,56 & 26 & 22,23 & 13 & 11,12 \\
Sikap & & & & & & \\
$\quad$ Baik & 14 & 11,96 & 36 & 30,77 & 55 & 47,00 \\
$\quad$ Cukup & 46 & 39,32 & 50 & 42,74 & 42 & 35,90 \\
$\quad$ Kurang & 57 & 48,72 & 31 & 26,49 & 20 & 17,10 \\
\hline
\end{tabular}

Sumber: Data Primer, 2015

Tabel 3. Perubahan Skor Pengetahuan dan Sikap Pemakaian Alat Kontrasepsi Sebelum dan Sesudah Penyuluhan (Pre - Post I - Post II)

\begin{tabular}{lccccccc}
\hline \multicolumn{1}{c}{ Variabel } & Pre & Post I & Beda & Nilai p & $\begin{array}{c}\text { Post II } \\
(\mathbf{3})\end{array}$ & $\begin{array}{c}\text { Beda } \\
\mathbf{( 3 - 1 )}\end{array}$ & Nilai p \\
\hline Pengetahuan & 3,25 & 8,07 & 4,77 & 0,002 & 8,53 & 5,3 & 0,000 \\
Sikap & 5,01 & 8,28 & 3,28 & 0,004 & 8,68 & 3,84 & 0,000 \\
\hline
\end{tabular}

Sumber: Data Primer, 2015

akan mampu bertahan lama dari pada yang tidak didasari oleh pengetahuan. Salah satu strategi untuk memperoleh perubahan perilaku menurut WHO yang dikutip oleh Notoatmodjo dalam Lestari dengan pemberian informasi untuk meningkatkan pengetahuan sehingga menimbulkan kesadaran dan pada akhirnya orang akan berperilaku sesuai dengan pengetahuannya, dan salah satu upaya pemberian informasi yang dapat dilakukan adalah dengan melakukan penyuluhan. ${ }^{11}$

Hasil penelitian menunjukkan bahwa jarak kehamilan, pengaturan jumlah anak dan peningkatan kesejahteraan keluarga merupakan prengaruh yang paling dirasakan bagi para peserta KB. Dengan kata lain dapat dikatakan bahwa pengaruh penyuluhan terhadap tiga faktor sangat besar dirasakan keberhasilannya oleh peserta KB. Tingkat pengetahuan responden merupakan faktor penting yang sangat menentukan dalam memutuskan untuk ber-KB. Rendahnya peserta KB pria disebabkan oleh terbatasnya metode atau cara kontrasepsi yang tersedia dan masih menganggap partisipasi pria tidak penting dilakukan serta pandangan yang cenderung menyerahkan tanggung jawab pelaksanaan KB dan kesehatan reproduksi sepenuhnya kepada wanita. ${ }^{12}$
Informasi mengenai alat kontrasepsi sangat penting dipahami sebelum memutuskan menggunakan alat kontasepsi tertentu. Dengan berbekal pengetahuan mengenai alat-alat kontarsepsi, beserta efek samping yang ditimbulkannya, kekurangan dan kelebihannya. Masyarakat dapat menentukan pilihan alat kontrasepsi yang sesuai sehingga memberi pengayoman lebih tinggi yang akhirnya akan meningkatkan kelestariannya dalam berkeluarga berencana. Jadi, pengetahuan mengenai alat-alat kontrasepsi beserta efek samping, kekurangan dan kelebihan sangat diperlukan untuk menentukan pilihan alat kontrasepsi yang akan digunakan serta untuk mendukung program KB yaitu agar masyarakat lebih menggunakan alat kontarsepsi yang efektif. ${ }^{13}$

Setiap anak merupakan cerminan harapan serta keinginan orang tua yang menjadi pedoman dari pola pikir, sikap maupun perilaku dari orang tua tersebut. Dengan demikian, setiap anak yang dimiliki oleh pasangan suami istri akan memberikan pertimbangan tentang keinginan memiliki anak dan jika ingin, jumlah yang diinginkan. ${ }^{14} \mathrm{Se}-$ hingga wanita dapat mengambil keputusan yang tepat tentang cara atau alat kontrasepsi yang akan dipakai. Jumlah anak hidup yang dimiliki seorang 
wanita, akan memberikan pengalaman, pengetahuan dan sikap yang baik mengenai pemakaian alat kontrasepsi lebih cenderung berkeinginan anak dalam jumlah sedikit dengan mempertimbangkan aspek kesehatan dan kemampuan untuk memberikan pendidikan yang layak. ${ }^{15}$

Selain itu, jumlah anak hidup memengaruhi pasangan usia subur dalam menentukan alat kontrasepsi yang akan digunakan. Pada pasangan dengan jumlah anak hidup masih sedikit terdapat kecenderungan untuk menggunkan metode kontrasepsi dengan tingkat efektivitas rendah, sedangkan pada pasangan dengan jumlah anak hidup banyak terdapat kecenderungan menggunkaan alat kontrasepsi dengan tingkat efektifitas tinggi. ${ }^{16}$ Saran bagi ibu yang telah memiliki anak banyak, yang ingin mengatur jarak kehamilan atau bahkan memiliki anak lagi dianjurkan untuk menggunakan alat kontrasepsi jangka panjang yang memiliki efektifitas yang tinggi, sehingga kemungkinan untuk mengalami kehamilan lagi cukup rendah. ${ }^{17}$

Tujuan umum pelayanan kontrasepsi adalah pemberian dukungan dan penetapan gagasan KB yaitu dihayati NKKBS. NKKBS menganjurkan setiap pasangan keluarga hanya mempunyai dua anak saja. Pasangan usia subur yang telah memiliki anak satu, cara KB yang efektif adalah KB hormonal maupun AKDR, sedangkan pasangan usia subur dengan dua anak dan lebih dan telah mencapai umur 30 tahun atau lebih dianjurkan untuk mengakhiri kesuburannya dengan menggunakan kontrasepsi. ${ }^{18}$

Sasaran program $\mathrm{KB}$ adalah seluruh $\mathrm{Pa}$ sangan Usia Subur (PUS) baik yang menunda kelahiran anak pertama (postponing), menjarangkan anak (spaling) maupun membatasi jumlah anak yang diinginkan (limiting). Semua sasaran diatas berperan penting. Karena keterbatasan waktu peneliti sehingga yang hanya menjadi bagian sasaran dari penelitian ini hanya pasangan usia subur yang termasuk kedalam golongan risiko tinggi (limiting phase). Fase penghentian kehamilan/kesuburan istilah lain adalah fase pembatasan kelahiran (limiting phase) merupakan suatu fase seorang ibu masuk dalam kategori risiko tinggi dalam melahirkan yaitu yang usia $>34$ tahun dengan paritas $>3 .{ }^{19}$

\section{KESIMPULAN DAN SARAN}

Berdasarkan uraian hasil dapat disimpulkan bahwa ada perubahan tingkat pengetahuan masyarakat sebelum dan sesudah dilakukan penyuluhan tentang jarak kehamilan, pengaturan jumlah anak dan tingkat kesejahteraan keluarga terhadap peningkatan pemakaian alat kontrasepsi di Kota Parepare. Ada perubahan sikap masyarakat sebelum dan sesudah dilakukan penyuluhan tentang jarak kehamilan, pengaturan jumlah anak dan tingkat kesejahteraan keluarga terhadap peningkatan pemakaian alat kontrasepsi di Kota Parepare. Bagi ibu yang telah memiliki anak banyak dan ingin mengatur jarak kelahiran atau bahkan tidak ingin memiliki anak lagi dianjurkan untuk menggunakan alat kontrasepsi jangka panjang yang memiliki efektifitas yang tinggi, sehingga kemungkinan untuk mengalami kehamilan lagi cukup rendah. Bagi instansi terkait diharapkan lebih meningkatkan konseling mengenai jenis kontrasepsi, cara pemasangan dan efek samping kontrasepsi kepada calon akseptor KB melalui poster dan informasi yang disisipkan dalam kegiatan kemasyarakatan seperti posyandu, pertemuan kader dan penyuluhan $\mathrm{KB}$.

\section{DAFTAR PUSTAKA}

1. Tajuddin F. Beberapa Faktor yang Mempengaruhi Pemilihan Jenis Kontrasepsi Pasangan Usia Subur Keluarga Miskin di Kelurahan Lapadde Kecamatan Ujung Kota Parepare [Skripsi]. Parepare: Universitas Muhammadiyah Parepare; 2009.

2. Sujudi A. Sistem Kesehatan Nasional. Jakarta: Departemen Kesehatan Republik Indonesia; 2014.

3. Munro, dkk. Penyuluhan Counselling. Suatu Pendekatan Berdasarkan Keterampilan. Jakarta: Ghalia Indonesia; 2003.

4. Hartanto, H. KB Keluarga Berencana dan Kontrasepsi. Jakarta: Pustaka Sinar Harapan; 2004.

5. Fienalia A R.. Faktor-Faktor yang Berhubungan dengan Penggunaan Metode Kontrasepsi Jangka Panjang di Wilayah Kerja Puskesmas Pancoran Mas Kota Depok tahun 2012. [serial online] http:lontar.ui.ac.id/file?file=digital/20294580-S Rainy\%20Alus\%20Fienalia; 2012 [25 April 2015].

6. Badan Koordinasi Keluarga Berencana Nasional. Profil Hasil Pendataan Keluarga Tahun 
2010. Makassar: BKKBN; 2010.

7. Badan Keluarga Berencana Pemberdayaan Perempuan. Pedoman Pengelolaan Program Keluarga Berencana Nasional. Parepare: BKBPP; 2012.

8. Gustikawati. Faktor Pendukung dan Penghambat Istri Pasangan Usia Subur dalam Menggunakan Alat Kontrasepsi di Puskesmas Denpasar Utara [Tesis]. Denpasar : Universitas Udayana;2014.

9. Rahman. Faktor-Faktor yang Berhubungan dengan Pemakaian Alat Kontrasepsi di Kabupaten Pinrang [Skripsi]. Parepare: Universitas Muhammadiyah Parepare; 2008.

10. Sugiyono. Metodologi Penelitian Administrasi. Bandung: Penerbit Alfabeta; 2008.

11. Lestari S. Perubahan Perilaku (Pengetahuan dan Sikap) Manajemen Laktasi setelah Edukasi pada Ibu Hamil di Kota Parepare [Skripsi]. Parepare: Universitas Muhammadiyah Parepare; 2011.

12. Kartono A. Program Pembinaan Ibu dan Anak. Makassar: Dinas Kesehatan Provinsi Sulawesi Selatan; 2002.

13. Arikunto S. Prosedur Penelitian Suatu
Pendekatan Praktik, Edisi Revisi VI Cetakan Ketiga Belas. Jakarta: PT. Rineka Cipta; 2006. 14. Affandi B. Penanggulangan Komplikasi Kontrasepsi Mantap. Jakarta : Pelkesi; 2006.

15. Arikunto S. Prosedur Penelitian Suatu Pendekatan Praktik, Edisi Revisi VI Cetakan Ketiga Belas. Jakarta: PT. Rineka Cipta; 2006.

16. Nasution SL. Faktor-faktor yang Mempengaruhi Penggunaan MKJP di Enam Wilayah Indonesia. 2011. [Serial Online] http:www. bkkbn.go.id. [Diakses 25 April 2015].

17. Istranti. Alat Kontrasepsi Jangka panjang. 2014 [Serial Online] http:www.bkkbn.go.id. [Diakses 25 April 2015].

18. Sriwahyuni E. Hubungan antara Jenis dan Lama Pemakaian Alat Kontrasepsi Hormonal dengan Peningkatan Berat Badan Akseptor. The Indonesia Journal of Public Health. 2013;8(3).

19. Setiowati T. Faktor-Faktor yang Berhubungan dengan Penggunaan Alat Kontrasepsi dalam Rahim pada Akseptor KB Golongan Risiko Tinggi di Puskesmas Wilayah Kecamatan Cimahi Selatan Kota Cimahi. 2014. The Indonesia Journal of Public Health: 8(3). 